\title{
Viabilidade De SEMEnTES DE ERVA-DE-TOURO, SOB DIFERENTES CONDIÇÕES DE ARMAZENAMENTO ${ }^{1}$
}

\author{
Seed Viability of Coat Button under Different Storage Conditions
}

GUIMARÃES, S.C. ${ }^{2}$, SOUZA, I.F. ${ }^{3}$ e PINHO, E.V.R.V. ${ }^{3}$

\begin{abstract}
RESUMO - A manutenção da viabilidade das sementes é muito influenciada pelas condições de armazenamento. No caso das plantas daninhas, essa informação pode servir como suporte para a realização de outras pesquisas e também ajudar na compreensão da dinâmica das infestações. Neste trabalho, a viabilidade das sementes da planta daninha erva-de-touro (Tridax procumbens) foi monitorada durante dois anos, quando armazenadas em câmara fria (temperatura de $10{ }^{\circ} \mathrm{C}$ e umidade relativa de $50 \%$ ), em congelador $\left(-18{ }^{\circ} \mathrm{C}\right)$, em armazém convencional (condições não controladas) e no solo. Quando armazenado em câmara fria (em sacos de papel) e em congelador (em tubos plásticos herméticos), o lote de sementes mantém a viabilidade inicial $(70,5 \%)$ por no mínimo 730 dias (período experimental). No solo, ocorre perda de viabilidade com o tempo, numa taxa constante de $8,2 \%$ para cada 100 dias. Em armazém convencional, a viabilidade das sementes (em sacos de papel) é mantida por 200 dias, com redução acentuada entre 300 e 500 dias, chegando ao final de 730 dias com 2,8\% de viabilidade. Em nenhuma das formas de armazenamento há indução de dormência secundária nas sementes.
\end{abstract}

Palavras-chave: Tridax procumbens, planta daninha, longevidade, banco de sementes.

\begin{abstract}
Seed viability is strongly influenced by storage conditions. In weeds, this information may serve as support for other research works and help to understand infestation dynamics as well. This work, conducted at Universidade Federal de Lavras, was carried out to evaluate the viability of coat button (Tridax procumbens) seeds stored in cold chamber ( temperature of $10^{\circ} \mathrm{C}$ and relative humidity of 50\%), in freezer $\left(-18^{\circ} \mathrm{C}\right)$, conventional warehouse (uncontrolled conditions) and soil, over 2 years. Seed lot with 70.5\% initial viability, maintained this condition over the experimental period (730 days) when stored in cold chamber (in paper bags) and in freezer (in airtight plastic tubes). Under soil conditions, viability loss occurred with time, at a constant rate of $8.2 \%$ at every 100 days. In a conventional warehouse, seed lot viability (in paper bag) was maintained for 200 days but there was a fast reduction between 300 and 500 days, and at the 730 days end only $2.8 \%$ of the seeds were viable. In none of the storage forms, there was induction of secondary dormancy in seeds.
\end{abstract}

Key words: Tridax procumbens, weed, longevity, seed bank.

\section{INTRODUÇÃO}

A manutenção da viabilidade das sementes após a dispersão é de grande significado ecológico para as espécies, porque permite sua distribuição no tempo e no espaço e garante a preservação de genes selecionados em diferentes ambientes ao longo dos anos. Nas plantas cultivadas, essa característica possibilita a semeadura nas épocas mais propícias à obtenção de resultados econômicos e à conservação e intercâmbio de germoplasma. Por outro lado, a manutenção da viabilidade nas plantas daninhas dá origem aos bancos

Recebido para publicação em 4.9.2003 e na forma revisada em 18.6.2004.

2 Prof. da Universidade da Federal de Mato Grosso - UFMT/FAMEV/DFF, 78060-900 Cuiabá-MT. ${ }^{3}$ Prof. da Universidade Federal de Lavras - UFLA/DAG, 37200-000 Lavras-MG. 
de sementes no solo, responsáveis pelas reinfestações nos campos de cultivo, que geram grandes perdas econômicas à atividade agropecuária e problemas ambientais, em razão das práticas adotadas para seu manejo.

Há uma grande variabilidade entre as espécies quanto à longevidade das suas sementes. Os levantamentos bibliográficos (Harrigton, 1972; Mayer \& Poljakoff-Mayber, 1989; Carmona, 1992; Bewley \& Black, 1994; Basu, 1995) incluem, num extremo, espécies cuja viabilidade das sementes somente é mantida por períodos inferiores a um ano e, noutro, aquelas que ainda germinam após mais de um século de liberadas da planta-mãe. No solo, embora existam espécies cujas sementes mantêm a viabilidade por vários anos (Kivilaan \& Bandurski, 1973), a maioria não germina após cinco anos (Egley \& Chandler, 1983). Nesse ambiente, as sementes com longevidade inferior a um ano após a dispersão formam o banco de sementes transitório, e, quando excedem esse período, dão origem ao banco de sementes persistente (Grime, 1981).

Embora o fator genético seja preponderante no estabelecimento da longevidade potencial das sementes, as condições de armazenamento irão definir, para cada espécie e lote, o período de viabilidade dentro do limite máximo determinado pelo genoma (Harrigton, 1972; Mayer \& Poljakoff-Mayber, 1989; Smith \& Berjak, 1995; Baskin \& Baskin, 1998). Umidade relativa do ar e temperatura são os fatores que mais influenciam a viabilidade de um lote de sementes durante o armazenamento (Basu, 1995; Smith \& Berjak, 1995; Walters, 1998), existindo uma regra prática que prognostica que o tempo de viabilidade é dobrado para cada decréscimo de $1 \%$ no conteúdo de umidade da semente ou $5{ }^{\circ} \mathrm{C}$ na temperatura ambiente (Harrigton, 1972). Nesse sentido, tem sido observado que, de modo geral, maiores longevidades ocorrem em sementes com tegumento impermeável à água e/ou mantidas em ambientes mais secos e frios (Harrigton, 1972; Mayer \& PoljakoffMayber, 1989; Basu, 1995; Smith \& Berjak, 1995). Por outro lado, sementes de várias espécies conservam sua viabilidade no solo por longos períodos (Taylorson, 1983), às vezes décadas (Kivilaan \& Bandurski, 1973), passando por fases em que permanecem completamente embebidas; acredita-se que nessa situação a viabilidade é mantida porque elas seriam capazes de operar os mecanismos reparadores de danos (Villiers, 1974; Villiers \& Edgcumbe, 1975). Assim, situações de umidade intermediárias seriam as mais prejudiciais, pois favoreceriam a deterioração das sementes e não seriam suficientes para ativar processos para sua reparação (Mayer \& Poljakoff-Mayber, 1989). Os limites mínimos de umidade e temperatura são específicos, existindo sementes de espécies que toleram o congelamento e/ou técnicas especiais de criopreservação, condições estas que podem prolongar a longevidade por periodos extremamente longos (Harrigton, 1972; Bewley \& Black, 1994; Wilson, 1995).

A erva-de-touro é uma planta daninha de importância recente no Brasil, muito freqüente no Centro-Oeste brasileiro. Embora ela se reproduza por sementes, existem poucas informações sobre a viabilidade desses órgãos, cujo conhecimento poderá ajudar no entendimento da dinâmica da infestação da espécie e também auxiliar na conservação de seus diásporos para fins experimentais.

Estudos sobre a preservação da viabilidade em sementes de erva-de-touro não foram encontrados na literatura, à exceção de um trabalho realizado na África, em que se observou que $7 \%$ das sementes permaneceram viáveis após dois anos no solo (Lutzeyer \& Koch, 1992). Dados adicionais foram obtidos em artigos publicados sobre germinação e/ou dormência, nos quais se verificou que lotes de sementes de erva-de-touro mantidos a $30{ }^{\circ} \mathrm{C}$, ou a $4^{\circ} \mathrm{C}$, ainda mantinham individuos viáveis após 18 meses (Popay, 1974) e que, em vasos com substrato de solo, ocorreu emergência de plântulas 22 meses após a semeadura (Popay, 1975). Assim, com o objetivo de ampliar essas informações, foi planejada a presente pesquisa, que monitorou a viabilidade das sementes da erva-de-touro, durante dois anos, em solo, câmara fria, armazém e congelador.

\section{MATERIAL E MÉTODOS}

Os aquênios da erva-de-touro (Tridax procumbens L.) foram coletados em plantas cultivadas em canteiros, no município de Lavras-MG, a partir de sementes de uma 
população há vários anos infestando culturas de soja e milho no município de RondonópolisMT. Os capitulos foram colhidos quando havia pelo menos um aquênio com papilho aberto e deixados secar à sombra, para facilitar o desprendimento dos frutos. Depois de retirados dos capítulos, os aquênios passaram por seleção visual, descartando-se os provenientes de flores femininas e aqueles com evidência de não possuírem sementes (de coloração branca) ou com sementes mal formadas.

Os aquênios selecionados foram embalados e armazenados em câmara fria (temperatura de $10{ }^{\circ} \mathrm{C}$ e umidade relativa do ar de $50 \%$ ), em armazém convencional (condições de temperatura e umidade relativa do ar apresentadas na Figura 1), em congelador (temperatura de $-18{ }^{\circ} \mathrm{C}$ ) e em canteiro a céu aberto, a $20 \mathrm{~cm}$ de profundidade (condições de temperatura e precipitação apresentadas na Figura 2). Foram armazenadas 24 amostras
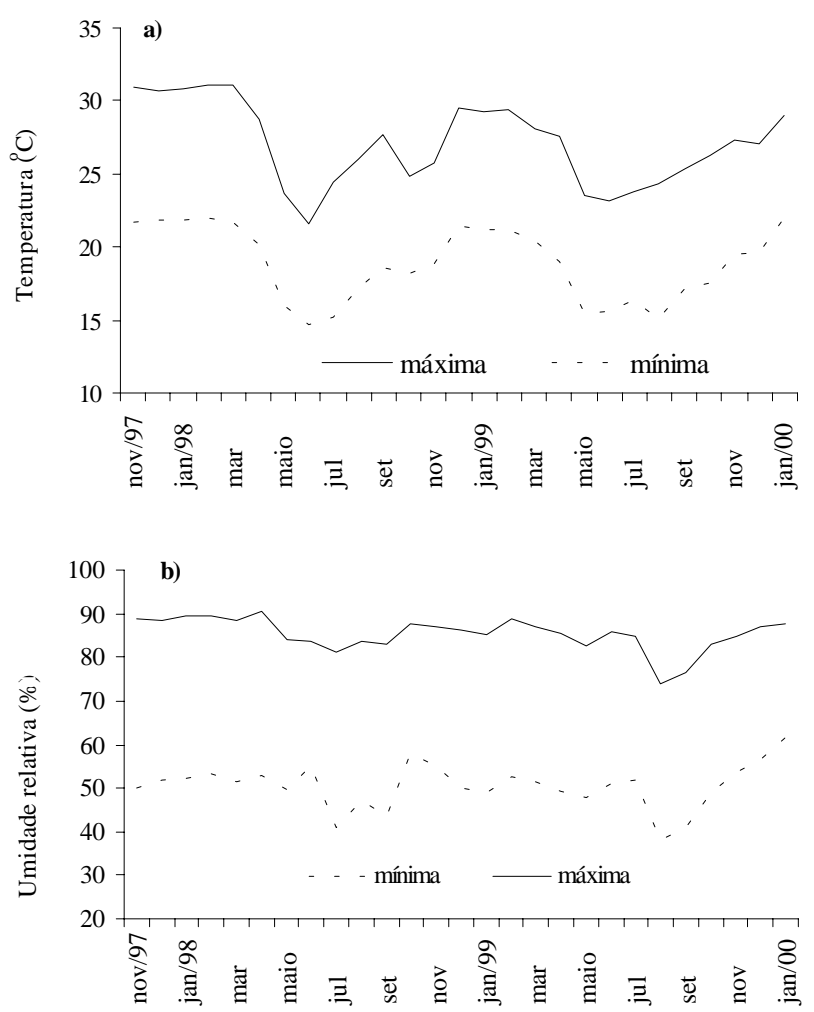

Figura 1 - Médias mensais de temperatura (a) e umidade relativa do ar (b), registradas no armazém convencional, durante o período de novembro de 1997 a janeiro de 2000. UFLA, Lavras-MG, 2000. em cada ambiente, no dia 02/12/1997, época em que os aquênios completavam de 4 a 10 dias após a coleta. O acondicionamento dos aquênios foi realizado em sacos de papel (250 sementes por embalagem), para o armazenamento em câmara fria e armazém, e em tubos plásticos herméticos (100 aquênios por tubo), para o armazenamento em congelador. Para a inumação nos canteiros, cada amostra foi composta por 250 aquênios, embalados em tecido sintético permeável $(90 \%$ de poliamida e $10 \%$ de elastano), misturados em $230 \mathrm{~mL}$ de substrato de solo contendo $30 \%$ de argila. Durante o periodo experimental, os canteiros foram naturalmente vegetados por várias espécies de plantas daninhas.

Foram feitas avaliações de viabilidade das sementes após 101, 220, 363, 440, 615 e 730 dias de armazenamento, pelo teste de germinação, complementado com o teste de tetrazólio.


Figura 2 - Médias mensais de temperaturas (a) e precipitações (b), registradas durante o período de armazenamento, em área próxima aos canteiros onde foram inumados os aquênios da erva-de-touro. UFLA, Lavras-MG, 2000.

Planta Daninha, Viçosa-MG, v.22, n.2, p.231-238, 2004 
O teste de germinação foi efetuado em caixas plásticas tipo do "gerbox", entre duas folhas de papel mata-borrão, umedecidas até o ponto de saturação do papel e mantidas em câmaras a $30{ }^{\circ} \mathrm{C}$ sob 12 horas diárias de luz (Guimarães et al., 2000b). Cada caixa recebeu 100 aquênios, e os tratamentos foram repetidos quatro vezes. Para compor as unidades experimentais foram utilizadas, em cada período de avaliação, quatro amostras provenientes de congelador e duas das demais formas de armazenamento. Foi contado diariamente o número de sementes germinadas, assim consideradas aquelas com qualquer estrutura de plântula visivel. As sementes não germinadas em 30 dias foram submetidas ao teste de tetrazólio, para verificação da viabilidade. Para a realização deste teste, como as sementes já se encontravam previamente embebidas, utilizou-se solução do sal de tetrazólio na concentração de $1 \%$, a $30^{\circ} \mathrm{C}$, por três dias. Foram consideradas viáveis as sementes que apresentavam estruturas fundamentais com coloração róseo-avermelhada.

Nos dois últimos períodos de avaliação, o material exumado do canteiro não apresentava aquênios intactos, não sendo possivel isolar as pequenas sementes do substrato. Nesses casos, a viabilidade foi estimada com base na emergência de plântulas ocorridas a partir da distribuição de duas amostras de substrato+ sementes (500 sementes), em finas camadas (3-5 mm), sobre duas folhas de papel mataborrão, em oito caixas plásticas do tipo "gerbox", mantidas nas mesmas condições do teste de germinação.

Com base nos resultados da germinação diária, foram calculados, para cada unidade experimental, a porcentagem de indivíduos viáveis e o índice de velocidade de germinação - este conforme metodologia proposta por Maguire (1962). Esses dados foram submetidos à análise de variância, estudando-se os efeitos de tempo de armazenamento, em cada ambiente, por meio de análise de regressão, e os efeitos de ambiente, nos diferentes períodos de armazenamento, por teste de comparação de médias (Scott e Knott a 5\% de probabilidade).

\section{RESULTADOS E DISCUSSÃO}

Todas as sementes que não germinaram durante o teste de germinação foram classificadas como inviáveis pelo teste de tetrazólio. Assim, o teste de germinação foi utilizado como medida da viabilidade dos tratamentos. Embora o teste tenha sido realizado durante 30 dias, todas as sementes viáveis germinaram num período máximo de 15 dias.

A análise de variância dos resultados de viabilidade permitiu concluir que essa variável sofreu a influência do ambiente e do tempo de armazenamento, havendo interação entre esses fatores $(p<0,05)$.

Na Figura 3 são mostrados os resultados da germinação final (viabilidade) em função dos ambientes e dos períodos de armazenamento.

Quando armazenadas em câmara fria e em congelador, as sementes da erva-de-touro mantiveram a viabilidade durante todo o período experimental, indicando que essas condições seriam suficientes para a conservação desses órgãos por no mínimo dois anos. Por outro lado, as sementes que permaneceram no solo ou no armazém convencional tiveram grandes perdas de viabilidade no período. No solo, a perda de viabilidade foi linear, estimada em $8,2 \%$ a cada 100 dias; o lote, que inicialmente tinha $70,5 \%$ de viabilidade, chegou aos 730 dias com 10,2\% (valor observado). No armazém, a perda de viabilidade das sementes, no período, seguiu um modelo polinomial de terceiro grau, com pequena redução nos primeiros 200 dias, mas intensificando-se muito entre 300 e 500 dias; ao final do periodo de armazenamento a viabilidade estava reduzida a 2,8\% (valor observado).

Como os lotes de sementes, de modo geral, são constituídos por indivíduos com diferentes graus de vigor (Basu, 1995; Wilson, 1995; Walters, 1998), é possivel que a parte menos vigorosa da população seja mais sensivel às condições reinantes no solo do que no armazém, justificando assim, nas avaliações iniciais, a maior viabilidade das sementes no armazém. A partir dos 300 dias, coincidindo com um aumento na temperatura e umidade relativa do ar (Figura 1), ocorreu rápido decréscimo na viabilidade das sementes no armazém, que aos 396 dias tornou-se semelhante àquela verificada no solo. Nesse ponto, a viabilidade nos dois lotes era de $37,3 \%$, ou seja, o número de indivíduos viáveis tinha sido 
reduzido próximo à metade $(47,1 \%)$. Nas avaliações seguintes, até o final do ensaio, a viabilidade foi menor nas sementes mantidas em armazém.

Sementes ortodoxas têm boa conservação em ambientes com temperatura e umidade mais baixas, e muitas delas também suportam temperaturas abaixo de $0{ }^{\circ} \mathrm{C}$ (Harrigton, 1972; Bewley \& Black, 1994; Wilson, 1995). As sementes de erva-de-touro seguiram esse padrão, mantendo a viabilidade quando armazenadas a $10^{\circ} \mathrm{C}$ e $50 \%$ de umidade relativa (câmara fria), ou mesmo quando colocadas diretamente em congelador $\left(-18^{\circ} \mathrm{C}\right)$. Esses resultados ampliam as informações contidas no trabalho de Popay (1974), no qual sementes dessa espécie mantiveram a viabilidade quando armazenadas a $4{ }^{\circ} \mathrm{C}$. No entanto, na presente pesquisa, pôde-se verificar que, quando sujeitas às variações de temperatura ambiente e umidade relativa do ar, como as ocorridas no armazém, as sementes de ervade-touro sofrem grande redução de viabilidade no período de um ano, indicando que essas condições não são seguras para a sua conservação. Como essas oscilações climáticas também ocorrem na superficie do solo, é possivel especular que a perda de viabilidade deva ser um importante fator de depleção no banco de sementes dessa espécie.

A grande diferença de viabilidade entre os resultados no solo e em condições controladas reforça a importância de se gerarem informações em condições naturais para os estudos

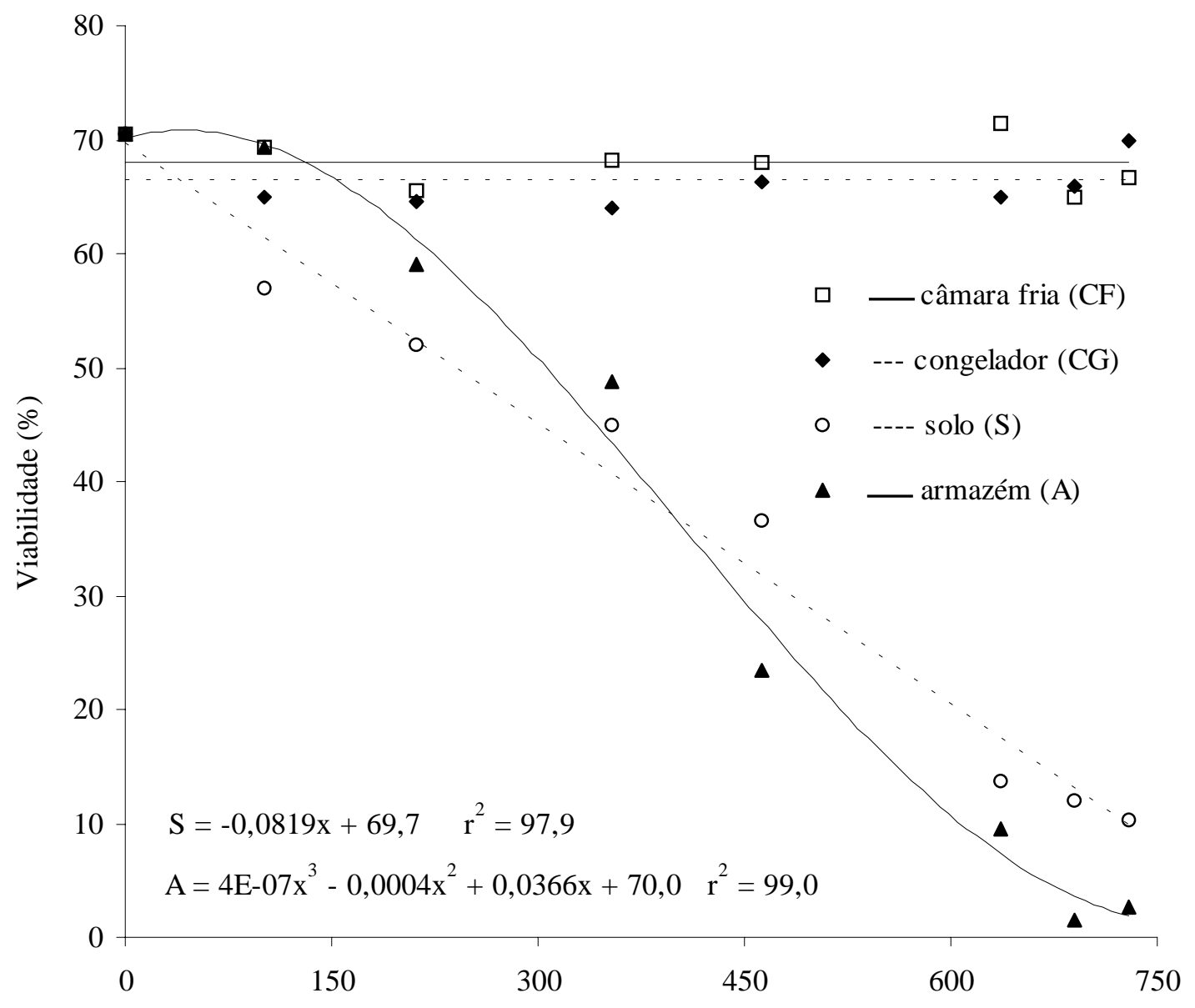

Dias de armazenamento

Figura 3 - Viabilidade de sementes de erva-de-touro, durante 730 dias, quando armazenadas em câmara fria, congelador, armazém convencional e solo. UFLA, Lavras-MG, 2000. 
de dinâmica de bancos de sementes, conforme evidenciado por Karssen \& Bouwmeester (1992). Nesse ponto, deve-se salientar que, na presente pesquisa, as sementes foram enterradas a $20 \mathrm{~cm}$ de profundidade, condição em que ficam menos expostas à ação de predadores e de microrganismos e também às variações bruscas de temperatura e umidade (Karssen \& Boumeester, 1992; Fenner, 1995).

O fato de as sementes de erva-de-touro, no solo, perderem $50 \%$ de viabilidade em um ano sugere que a grande produção desses diásporos pela espécie, conforme verificado por Guimarães et al. (2000a), deve ter grande importância na formação de seu banco de sementes, garantindo as reinfestações periódicas da planta daninha. Como o número de sementes viáveis decresce para cerca de $10 \%$ em dois anos, fato também verificado por Lutzeyer \& Koch (1992), e como ocorre rápida germinação em ambientes favoráveis, pode-se


$$
\begin{aligned}
& \multimap 101 \rightarrow-220 \rightarrow-363 \\
& \triangle 440 \quad-615 \quad \square-730
\end{aligned}
$$

Figura 4 - Germinação acumulada de sementes de erva-detouro, após diferentes períodos de armazenamento em câmara fria (a) e congelador (b). Viabilidade inicial do lote $=$ 70,5\%. UFLA, Lavras-MG, 2000. esperar que táticas de manejo que estimulem a germinação e evitem a entrada de novos diásporos no solo sejam muito eficazes na redução do banco de sementes. Nas Figuras 4 e 5 pode-se observar essa rápida resposta aos fatores ambientais favoráveis, o que foi confirmado pelos indices de velocidade de germinação (IVG) (Tabela 1), verificando-se que as sementes viáveis atingiram o máximo de germinação entre 6 e 9 dias, sendo esse período ainda menor no caso daquelas armazenadas no solo. Nesse caso, houve protrusão de radícula 24 horas após o fornecimento de luz às sementes, e a germinação máxima foi atingida entre 48 e 72 horas. Por isso, os valores de IVG, nas sementes armazenadas em solo, foram superiores àqueles observados nas sementes nos demais ambientes de armazenamento, mesmo nos períodos em que a viabilidade final já estava mais baixa em relação à câmara fria e ao congelador (Tabela 1).


$$
\begin{aligned}
& \rightarrow 101 \rightarrow-220 \rightarrow-363 \\
& \triangle 440 \quad-615 \quad \square-730
\end{aligned}
$$

Figura 5 - Germinação acumulada de sementes de erva-detouro, após diferentes períodos de armazenamento no solo (a) e em armazém convencional (b). Viabilidade inicial do lote $=70,5 \%$. UFLA, Lavras-MG, 2000 . 
Tabela 1 - Índice de velocidade de germinação para sementes de erva-de-touro, após diferentes períodos de armazenamento, em quatro ambientes. UFLA, LavrasMG, 2000

\begin{tabular}{|l|c|c|c|c|c|c|}
\hline \multirow{2}{*}{ Ambiente } & \multicolumn{6}{|c|}{ Período de armazenamento em dias } \\
\cline { 2 - 7 } & 101 & 220 & 363 & 440 & 615 & 730 \\
\hline Solo & $18,8 \mathrm{~A}$ & $16,4 \mathrm{~A}$ & $36,3 \mathrm{~A}$ & $26,1 \mathrm{~A}$ & - & - \\
\hline Armazém & $13,7 \mathrm{~B}$ & $13,0 \mathrm{~B}$ & $10,4 \mathrm{C}$ & $3,7 \mathrm{C}$ & $1,0 \mathrm{~B}$ & $0,5 \mathrm{~B}$ \\
\hline Câmara fria & $13,3 \mathrm{~B}$ & $12,1 \mathrm{~B}$ & $14,4 \mathrm{~B}$ & $12,3 \mathrm{~B}$ & $14,2 \mathrm{~A}$ & $15,0 \mathrm{~A}$ \\
\hline Congelador & $12,1 \mathrm{~B}$ & $11,9 \mathrm{~B}$ & $12,1 \mathrm{C}$ & $12,0 \mathrm{~B}$ & $14,1 \mathrm{~A}$ & $15,6 \mathrm{~A}$ \\
\hline
\end{tabular}

Médias nas colunas, marcadas com letras distintas, são estatisticamente diferentes (Scott e Knott, $\mathrm{p}<0,05$ ).

As sementes de erva-de-touro, mesmo embebidas, não germinam no solo a maiores profundidades em razão da ausência de luz (Guimarães et al., 2002), fator que só atinge niveis suficientes para a ativação do processo nos primeiros milimetros (Benvenuti, 1995). No entanto, quando embebidas, essas sementes permanecem em estádios avançados no processo de germinação, fase em que pode ocorrer reparo de danos bioquímicos em organelas vitais (Villiers, 1974; Villiers \& Edgcumbe, 1975), possibilitando uma rápida protrusão de radícula quando o fornecimento de luz se torna adequado.

A rápida germinação de todas as sementes viáveis de erva-de-touro durante o teste indica que não houve indução de dormência secundária durante o armazenamento. Esse fato pode em parte explicar a correlação obtida entre a vegetação dessa espécie e seu banco de sementes (Akinola \& Egunjobi, 1996a, b), resultados não facilmente observáveis em outras espécies (Baskin \& Baskin, 1998) e que dificultam o entendimento da dinâmica das populações e sua utilização no manejo das plantas daninhas.

Concluindo, as sementes de erva-de-touro mantêm a viabilidade por no mínimo 730 dias quando armazenadas em câmara fria (temperatura de $10{ }^{\circ} \mathrm{C}$ e umidade relativa de $50 \%$ ) e em congelador (temperatura de $-18{ }^{\circ} \mathrm{C}$ ). No solo, ocorre decréscimo linear da viabilidade com o tempo, numa taxa de $8,2 \%$ a cada 100 dias, e em armazém convencional a viabilidade é mantida por 200 dias, com redução acentuada no período entre 300 e 500 dias. Não há indução de dormência secundária nas sementes com o armazenamento.

\section{LITERATURA CITADA}

AKINOLA, M. D.; EGUNJOBI, J. K. Effect of soil applied herbicides on the weed seed bank and composition in maize and cowpea cropping systems in southwestern Nigeria. 1. Relationship between weed flora and their seed bank in the soil of a dry forest zone. Inter. J. Ecol. Environ. Sci., (India), v. 21, n. 3, p. 199-210, 1995; AGRICULTURAL AND ENVIRONMENT FOR DEVELOPING REGIONS, Amsterdam, v. 1, n. 9, p. 93, 1996a. (Abst. 102445.)

AKINOLA, M. D.; EGUNJOBI, J. K. Effect of soil applied herbicides on the weed seed bank and composition in maize and cowpea cropping systems in the south western Nigeria. 2. Relationship between weed flora and their seed bank in the soil of a derived savanna area. Inter. J. Ecol. Environ. Sci., (India), v. 21, n. 3, p. 211-220, 1995; AGRICULTURAL AND ENVIRONMENT FOR DEVELOPING REGIONS, Amsterdam, v. 1, n. 9, p. 93, 1996b. (Abst. 102446.)

BASKIN C. C.; BASKIN. J. M. Germination ecology of seeds in the persistent seed bank. In: __. Seeds: ecology, biogeography, and evolution of dormancy and germination. San Diego: Academic Press, 1998. p. 133-179.

BASU, R. N. Seed viability. In: BASRA, A. S. (Ed.) Seed quality: basic mechanisms and agriculture implications. New York: Food Products Press, 1995. p. 1-44.

BENVENUTI, S. Soil light penetration and dormancy of jinsonweed (Datura stramonium) seeds. Weed Sci., v. 43, n. 3, p. 389-393, 1995.

BEWLEY, J. D.; BLACK, M. Seeds: physiology of development and germination. 2.ed. New York: Plenum, 1994. $445 \mathrm{p}$.

CARMONA, R. Problemática e manejo de bancos de sementes de invasoras em solos agrícolas. Planta Daninha, v. 10, n. $1 / 2$, p. 5-16, 1992.

EGLEY, G. H.; CHANDLER, J. M. Longevity of weed seeds after 5.5 years in the Stoneville 50-year buried seed study. Weed Sci., v. 31, n. 2, p. 264-270, 1983.

FENNER, M. Ecology of seed banks. In: KIGEL, J. D.; GALILI, G. (Eds.) Seed development and germination. New York: Marcel Dekker, 1995. p. 507-528.

GRIME, J. P. The role of seed dormancy in vegetation dynamics. Ann. Appl. Biol., v. 98, n. 3, p. 555-558, 1981.

GUIMARÃES, S. C.; SOUZA, I. F.; PINHO, E. V. R. V. Capacidade reprodutiva da erva-de-touro. In: CONGRESSO BRASILEIRO DA CIÊNCIA DAS PLANTAS

DANINHAS, 22., 2000a, Foz do Iguaçu. Resumos... Foz do Iguaçu: SBCPD, 2000a. p. 43.

Planta Daninha, Viçosa-MG, v.22, n.2, p.231-238, 2004 
GUIMARÃES, S. C.; SOUZA, I. F.; PINHO, E. V. R. V. Efeito de temperaturas sobre a germinação de sementes de erva-de-touro (Tridax procumbens). Planta Daninha, v. 18, n. 3, p. 457-464, 2000 b.

GUIMARÃES, S. C.; SOUZA, I. F.; PINHO, E. V. R. V. Emergência Tridax procumbens em função da profundidade de semeadura, do conteúdo de argila no substrato e da incidência de luz na semente. Planta Daninha, v. 20, n. 3, p. 413-419, 2002.

HARRIGTON, J. F. Seed storage and longevity. In: KOZLOWSKI, T.T. (Ed.) Seed biology. New York: Academic Press, 1972. v. 3. p. 145-243.

KARSSEN, C. M.; BOUWMEESTER, H. J. Annual dormancy patterns of weed seeds influence weed control. In: INTERNATIONAL WEED CONTROL CONGRESS, 1., 1992, Melbourne. Proceedings... Melbourne: Weed Sci. Society of Victoria, 1992. p. 98-104.

KIVILAAN, A.; BANDURSKI, R. S. The ninety-year period for Dr. Beal's seed viability experiment. Am. J. Bot., v. 60, n. 2 , p. $140-145,1973$.

LUTZEYER, H. J.; KOCH, W. Seed survival and periodicity of seedling emergence of some important weeds in south Benin. In: GERMAN CONFERENCE ON WEED BIOLOGY AND CONTROL, 16., 1992, Stuttgard.

Zeitschrift fur Pflanzenkrankheiten und Pflanzenschutz, Sonderheft, v. 13, p. 87-93, 1992, CAB Abstracts, Wallingford, 1993-1994. (CD-ROM)

MAGUIRE, J. D. Speed of germination-aid in relation evaluation for seedling emergence vigor. Crop Sci., v. 2, n. 2, p. 176-177, 1962.
MAYER, A. M.; POLJAKOFF-MAYBER, A. The germination of seeds. 4.ed. Oxford: Pergamon Press, 1989. $270 \mathrm{p}$.

POPAY, A. I. Investigations into the behaviour of the seeds of some tropical weeds. I. Laboratory germination tests. E. Afr. Agric. For. J., v. 39, n. 1, p. 31-43, 1974.

POPAY, A. I. Investigations into the behaviour of the seeds of some tropical weeds. II. Dry soil storage and seasonal germination. E. Afr. Agric. For. J., v. 40, n. 4, p. 408-415, 1975 .

SMITH, M. T.; BERJAK, P. Deteriorative changes associate with the loss of viability of stored desiccationtolerant and desiccation-sensitive seeds. In: KIGEL, J. D.; GALILI, G. (Eds) Seed development and germination. New York: Marcel Dekker, 1995. p. 701-746.

TAYLORSON, R. B. Aspects of seed biology and physiology in Weed Science. Weeds Today, v. 14, n. 2, p. 3-4, 1983.

VILLIERS, T. A. Seed aging: chromossome stability and extend viability of seeds storage fully imbibed. Plant Physiol., v. 53, n. 6, p. 875-878, 1974.

VILLIERS, T.A.; EDGCUMBE, D.J. On the cause of seed deterioration in dry storage. Seed Sci. Technol., v. 3, n. 4/ 5, p. 761-774, 1975.

WALTERS, C. Understanding the mechanisms and kinetics of seed aging. Seed Sci. Res., v. 8, n. 2, p. 223-244, 1998.

WILSON Jr., D. O. The storage of orthodox seeds. In: BASRA, A. S. (Ed.) Seed quality: basic mechanisms and agriculture implications. New York: Food Products Press, 1995. p. 173-207. 